Article

\title{
Morphological Differentiation of Streptomyces clavuligerus Exposed to Diverse Environmental Conditions and Its Relationship with Clavulanic Acid Biosynthesis
}

\author{
Jeferyd Yepes-García ${ }^{\circledR}$, Carlos Caicedo-Montoya ${ }^{\circledR}$, Laura Pinilla, León F. Toro ${ }^{\mathbb{D}}$ \\ and Rigoberto Ríos-Estepa *(D) \\ Group of Bioprocesses, Chemical Engineering Department, University of Antioquia UdeA, Calle 70 No. 5221, \\ Medellín 050010, Colombia; jeferyd.yepesg@udea.edu.co (J.Y.-G.); candres.caicedo@udea.edu.co (C.C.-M.); \\ laura.pinilla@udea.edu.co (L.P.); lfelipe.toro@udea.edu.co (L.F.T.) \\ * Correspondence: rigoberto.rios@udea.edu.co
}

Received: 7 July 2020; Accepted: 28 July 2020; Published: 25 August 2020

\begin{abstract}
Clavulanic acid (CA) is a potent inhibitor of class A $\beta$-lactamase enzymes produced by Streptomyces clavuligerus (S. clavuligerus) as a defense mechanism. Due to its industrial interest, the process optimization is under continuous investigation. This work aimed at identifying the potential relationship that might exist between S. clavuligerus ATCC 27064 morphology and CA biosynthesis. For this, modified culture conditions such as source, size, and age of inoculum, culture media, and geometry of fermentation flasks were tested. We observed that high density spore suspensions $\left(1 \times 10^{7}\right.$ spores $\left./ \mathrm{mL}\right)$ represent the best inoculum source for $S$. clavuligerus cell suspension culture. Further, we studied the life cycle of $S$. clavuligerus in liquid medium, using optic, confocal, and electron microscopy; results allowed us to observe a potential relationship that might exist between the accumulation of CA and the morphology of disperse hyphae. Reactor geometries that increase shear stress promote smaller pellets and a quick disintegration of these in dispersed secondary mycelia, which begins the pseudosporulation process, thus easing CA accumulation. These outcomes greatly contribute to improving the understanding of antibiotic biosynthesis in the Streptomyces genus.
\end{abstract}

Keywords: clavulanic acid; Streptomyces clavuligerus; cell morphology; shear stress

\section{Introduction}

Clavulanic acid (CA) is a potent inhibitor of beta-lactamase enzymes, produced by the filamentous gram (+) bacterium Streptomyces clavuligerus (S. clavuligerus). Due to its industrial interest, diverse optimization strategies have been developed so as to overcome production drawbacks and low titers [1-3].

During its cell cycle in solid media, the Streptomyces genus has the capacity to form vegetative and reproductive mycelium, similar to filamentous fungi, and to produce spores at the extreme of the reproductive mycelium, once it undergoes starvation [4]. In liquid medium, the presence of compartmentalized (primary) mycelium (MI) has been observed, from which the multinuclear (secondary) mycelium (MII) emerges, prior to the sporulation process [5-7]. Special attention has been placed on the likely relationship that might exist between product accumulation and cell morphology or lifecycle stage [8-10]; for example, the synthesis of prodigiosin and actinorhodin by S. coelicolor has been related to the appearance and formation of secondary mycelium (MII) [7]. Moreover, production of 
erythromycin by S. erythraea is favored by the presence of larger clumps of mycelium [8,11]. In contrast, virginiamycin, an antibiotic produced by S. virginiae, is apparently not related to cell morphology [9].

The relationship between morphology and secondary metabolism is complex, considering that mycelium differentiation is one of the factors that triggers secondary metabolism and antibiotic production $[7,12,13]$. For the case of the Streptomyces morphology, research has shown that the presence of mycelial grouping in the medium (pellets and clumps of primary and secondary mycelium) affects product biosynthesis [7,14-16]. Moreover, authors have reported on specific genes involved in the morphological differentiation that affects secondary metabolism, such as $a d p A$, which is a regulatory gene immersed in the morphogenesis and spore formation pathway in S. clavuligerus [17].

Production of CA has been performed at the lab and industrial scales [18]. Previous studies were aimed at attaining larger CA titers by using complex media containing olive oil, isolated soy protein, soy flour, and sunflower oil [2,19-21]. Product biosynthesis is also affected by biomass concentration and its physiological state at the beginning of the cell suspension culture; hence, inoculum concentration impacts CA production $[10,21]$. According to Saudagar et al., during inoculum preparation, the presence of healthy and abundant metabolically active biomass $(3-10 \% v / v)$ must be considered along with its morphological conditions, in an attempt to avoid a prolonged lag phase during cultivation [1].

Neves et al. observed an increase of $22 \%$ in CA titers when the age and percentage of inoculum (mycelia) was $24 \mathrm{~h}$ and $14 \%$ of the bioreactor volume, respectively [21]; in addition, CA production appears to be related to spore-based inoculum concentration [22]. Similar results were found for erythromycin biosynthesis: A 3.5-fold reduction in antibiotic production was observed when spore concentration was changed from $1 \times 10^{6}$ to $1 \times 10^{3}$ spores $/ \mathrm{mL}$, at the beginning of cultivation [8,11].

Oxygen supply is another important factor in Streptomyces cell suspension culture for secondary metabolite production [23]. Concentration of dissolved oxygen strongly depends on the reactor geometry and homogenization system. Marín-Palacio et al. found a 2.5-fold increase in S. lividans biomass production along with a recombinant protein synthesis, when cells were grown in baffled Erlenmeyer flasks instead of flasks equipped with helical springs. Baffled Erlenmeyer flasks provide a higher interfacial area between gas and liquid, and, consequently, larger mass transfer coefficients [16,24].

Although morphological differentiation and its association with secondary metabolite production has been studied in some Streptomycetes model organisms, e.g., S. coelicolor and S. virginiae [6,9], similar investigations have been scarcely undertaken in S. clavuligerus; most of these studies aimed at understanding the relationship that might exist between the life cycle and CA production at flask scale, using mutant strains and a proteomic analysis $[15,17]$. However, flask geometries and their effect on CA production by S. clavuligerus have not been explored. In this contribution, we expose cells of S. clavuligerus ATCC 27064 to different environmental conditions to cause high and low shear stress forces so as to induce varied morphological phenotypes; it is expected that the study of these phenotypes could provide insights into the potential relationships that might exist between diverse mechanical stress conditions, the developed morphological states, and CA biosynthesis.

\section{Materials and Methods}

\subsection{Microorganism and Culture Media}

S. clavuligerus ATCC 27064 was used throughout this work. To activate the strain, mycelium samples of $500 \mu \mathrm{L}$, previously stored in glycerol $40 \%(v / v)$ at $-80{ }^{\circ} \mathrm{C}$, were cultured on plates with TSA (Trypticase Soy Agar, Acumedia-Neogen ${ }^{\circledR}$, Lansing, MI 48912, USA), during $48 \mathrm{~h}$ at $28^{\circ} \mathrm{C}$. After growth, plates were stored at $4{ }^{\circ} \mathrm{C}$ for a time interval smaller than 8 weeks.

A complex culture medium was used during all the experiments that included CA production and quantification, e.g., those described in Sections 2.3 and 2.5. The composition of the medium was as follows (in $\mathrm{g} / \mathrm{L}$ ): glycerol, 15; yeast extract, 1 ; malt extract, $10 ; \mathrm{K}_{2} \mathrm{HPO}_{4}$, 2.5; isolated soy protein, 10; 3-(N-morpholino)propanesulfonic acid (MOPS), 21; $\mathrm{MgSO}_{4} \cdot 7 \mathrm{H}_{2} \mathrm{O}, 0.75 ; \mathrm{FeSO}_{4} \cdot 7 \mathrm{H}_{2} \mathrm{O}, 0.001$; 
$\mathrm{MnCl}_{2} \cdot 4 \mathrm{H}_{2} \mathrm{O}, 0.001 ; \mathrm{ZnSO}_{4} \cdot 7 \mathrm{H}_{2} \mathrm{O}, 0.001$. Likewise, a TSB preculture (Trypticase Soy Broth, Merck ${ }^{\circledR}$, Darmstadt 64293, Germany), with $50 \mathrm{~mL}$ of broth at a concentration of $30 \mathrm{~g} / \mathrm{L}$, in a $250 \mathrm{~mL}$ baffled Erlenmeyer, was performed prior to the experiments, detailed in Sections 2.3 and 2.5. Conditions of the preculture, such as inoculum source, inoculum size, and running time, were selected according to the assays proposed in Sections 2.2 and 2.3.

For spores stock preparation, glycerol-preserved cells were transferred and cultivated in the GYM (glucose, yeast extract, and malt extract [25]) medium at $30^{\circ} \mathrm{C}$. After 14 days of culture, spore suspensions were obtained as described by Ghojavand et al. [8], and maintained at $-20^{\circ} \mathrm{C}$ in $20 \%$ sterile glycerol. Spore counting was performed as described by Hopwood et al. [26]. The stock of mycelium used for experiments carried out in Section 2.2 was obtained from a colony from the glycerol-preserved stock of spores, inoculated into a $50 \mathrm{~mL}$ TSB medium $(250 \mathrm{~mL}$ Erlenmeyer) and incubated for $36 \mathrm{~h}$ at $28{ }^{\circ} \mathrm{C}$ and $220 \mathrm{rpm}$ (rotary agitator New Brunswick). Aliquots of $500 \mu \mathrm{L}$ were then transferred to $1.5 \mathrm{~mL}$ Eppendorf tubes containing $500 \mu \mathrm{L}$ of $40 \%(v / v)$ sterile glycerol solution and stored at $-20{ }^{\circ} \mathrm{C}$. Average biomass concentration was calculated as $5.5 \pm 0.5 \mathrm{~g} / \mathrm{L}$, using the dry weight technique [2].

\subsection{Inoculum Studies}

S. clavuligerus inoculum sources were studied to identify differences in the associated culture growth rate and performance. For this, three different sources were explored: (i) spore suspension, (ii) mycelium stock, and (iii) 5-day old colonies, obtained from agar plates with the GYM medium (5 days is the time required by $S$. clavuligerus to develop primary mycelium on this medium). TSB ( $50 \mathrm{~mL}$ of broth at a concentration of $30 \mathrm{~g} / \mathrm{L}$, in a $250 \mathrm{~mL}$ baffled Erlenmeyer) was used as culture medium. Inoculation was as follows: (a) $500 \mu \mathrm{L}$ spore suspension $\left(1 \times 10^{3}-1 \times 10^{7}\right.$ spores $\left./ \mathrm{mL}\right)$, (b) $1 \mathrm{~mL}$ of mycelium stock and (c) $25 \mathrm{~mm}^{2}$ colonies growing on solid medium. All experiments were run by triplicates $\left(80 \mathrm{~h}, 220 \mathrm{rpm}, 28^{\circ} \mathrm{C}\right.$, and $\left.\mathrm{pH} 6.8\right)$.

Statistically significant differences in cell density, specific growth rate $(\mu)$, and doubling time $\left(t_{\mathrm{d}}\right)$ for the different treatment (inoculum sources) were analyzed through variance analysis (ANOVA) with a value significance threshold of 0.05 (Software R, R-3.2.2). A least significant difference (LSD) test was performed to differentiate among means, and superscripts $a, b, c$, and d were used to identify every group generated (the same letter on a different inoculum source means no significant differences between them, for either $\mu$ or $t_{\mathrm{d}}$ ). The inoculum source with a larger $\mu$ and lower statistical variation was selected for further experiments.

\subsection{Combined Effect of Age and Inoculum Concentration on Cell Growth and CA Production}

A three-level full factorial design $3^{2}$ was used to identify the effect of volume $(v / v)$, and incubation time (h) on CA concentration $(\mathrm{mg} / \mathrm{L}$ ) (response variable). For each assay, baffled Erlenmeyer flasks were used with $50 \mathrm{~mL}$ of production medium $\left(220 \mathrm{rpm}, 28^{\circ} \mathrm{C}\right)$. Culture conditions were set as follows: incubation time $36-72 \mathrm{~h}$; inoculum percentage $2.5-7.5 \%(v / v)$. A statistical analysis ( $\mathrm{R}$ version $\mathrm{R}-3.2 .2$ ) was performed using the response surface methodology (RSM) following a second order model:

$$
\hat{y}=b_{0}+\sum b_{i} x_{i}+\sum b_{i i} x_{i}^{2}+\sum b_{i j} x_{i} x_{j}
$$

where $\hat{y}$ is CA production; $x_{i}$ and $x_{j}$ are the lineal or individual factors (incubation time and inoculum concentration); $x_{i}^{2}$ is the quadratic factors; and $b_{0}, b_{i}, b_{i i}$, and $b_{i j}$ are the coefficients of each effect.

\subsection{Cell Cycle and Morphology Changes in S. Clavuligerus}

For S. clavuligerus cell cycle studies starting from spores, $500 \mu \mathrm{L}$ of spores suspension $\left(1 \times 10^{7}\right.$ spores $\left./ \mathrm{mL}\right)$ were inoculated into $50 \mathrm{~mL}$ of TSB medium $(250 \mathrm{~mL}$ baffled Erlenmeyer) and incubated at $28^{\circ} \mathrm{C}$, pH 6.8, $220 \mathrm{rpm}$, during $120 \mathrm{~h}$. Sampling $(20 \mu \mathrm{L})$ was carried out every twelve hours, and cell morphology was also observed, even at nutritional stress conditions. Cell cycle dynamics was 
observed using an optical Motic ${ }^{\circledR}$ BA 310 microscope equipped with Moticam ${ }^{\circledR}$ 5MP (Kowloon Bay, Hong Kong, China), and Software Images Plus 2.0.

Conformation and pellet structure were analyzed using propidium iodide (PI) and fluorescein diacetate (FDA) as probes. For this, $1 \mathrm{~mL}$ of the medium was centrifuged $\left(10,000 \mathrm{rpm}, 10 \mathrm{~min}, 25^{\circ} \mathrm{C}\right)$; the obtained pellet was suspended in $1 \mathrm{~mL}$ staining solution (Table 1). The processed samples were incubated in darkness (10 $\mathrm{min}$ ) and centrifuged; isolated pellets were suspended in fresh culture medium and analyzed in an Olympus IX81 confocal microscope.

Table 1. Staining solution components and excitation/emission wave lengths for confocal microscopy.

\begin{tabular}{ccccc}
\hline Component/Probe & Concentration & Volume Added & $\begin{array}{c}\text { Wavelength } \\
\text { (Excitation) }\end{array}$ & $\begin{array}{c}\text { Wavelength } \\
\text { (Emission) }\end{array}$ \\
\hline Culture medium & $30 \mathrm{~g} / \mathrm{L}$ & $5 \mathrm{~mL}$ & - & - \\
PI $^{*}$ & $5 \mathrm{mg} / \mathrm{mL}$ & $10 \mu \mathrm{L}$ & $470 \mathrm{~nm}$ & $520 \mathrm{~nm}$ \\
FDA $^{* *}$ & $20 \mathrm{mg} / \mathrm{mL}$ & $20 \mu \mathrm{L}$ & $534 \mathrm{~nm}$ & $618 \mathrm{~nm}$ \\
\hline
\end{tabular}

* PI stock solution was prepared by dissolving $20 \mathrm{mg}$ of PI in $1 \mathrm{~mL}$ Phosphate-buffered saline (PBS) (stored at $4{ }^{\circ} \mathrm{C}$ ).

** FDA stock solution was obtained by dissolving $5 \mathrm{mg}$ of FDA in $1 \mathrm{~mL}$ acetone (stored at $-20^{\circ} \mathrm{C}$ ).

Additionally, in order to study the relationship between CA production and cell morphology, biomass (pellets morphology), grown in the TSB seed medium, was inoculated in the chemically defined medium GSPA (Glycerol-Sucrose-Proline-Asparagine) and in the production (complex) culture medium (50 mL, pH 6.2, $220 \mathrm{rpm}$, baffled Erlenmeyer) [27]. Samples were taken starting at $72 \mathrm{~h}$ of fermentation to analyze morphology changes through optic microscopy and scanning electron microscopy (SEM).

SEM was used for morphological changes studies; this technique has been previously selected for detailing differences at the filament surface level, in diverse Streptomyces species [28]. For this, a $120 \mu \mathrm{L}$ medium was fixed on a glass plaque and submerged on glutaraldehyde $(2.5 \% v / v)$ for two hours. Then, plaques were washed with distilled water and dehydrated by immersion in ethanol solutions $(59,75$, 90, and $100 \% v / v$ ) during 15 min. Finally, samples were exposed to drying until the critical point was reached [29].

\subsection{Effect of Mechanical Stress on Biomass Growth and CA Production}

Mechanical stress was induced in three ways: (i) by a baffled Erlenmeyer $(250 \mathrm{~mL})$, (ii) by a helical spring (80/20 Nickel/Chrome, $0.5 \mathrm{~cm}$ external diameter) placed on the bottom of a standard Erlenmeyer $(250 \mathrm{~mL})$, and (iii) by $0.4 \mathrm{~mm}$ diameter glass beads submerged into a standard Erlenmeyer $(250 \mathrm{~mL})$. A standard smooth Erlenmeyer was used as a negative control (Figure 1).

Cell suspension cultures, previously grown in TSB, were run during $184 \mathrm{~h}\left(28^{\circ} \mathrm{C}\right.$ and $\left.220 \mathrm{rpm}\right)$ using the production (complex) culture medium; samples $(1 \mathrm{~mL})$ were taken daily, starting at the $72 \mathrm{~h}$ of culture, for CA and biomass quantification, and for image analysis through optical and SEM microscopes, as previously described. Statistically significant differences in biomass growth and CA biosynthesis were estimated, as described in Section 2.2 for inoculum studies. 


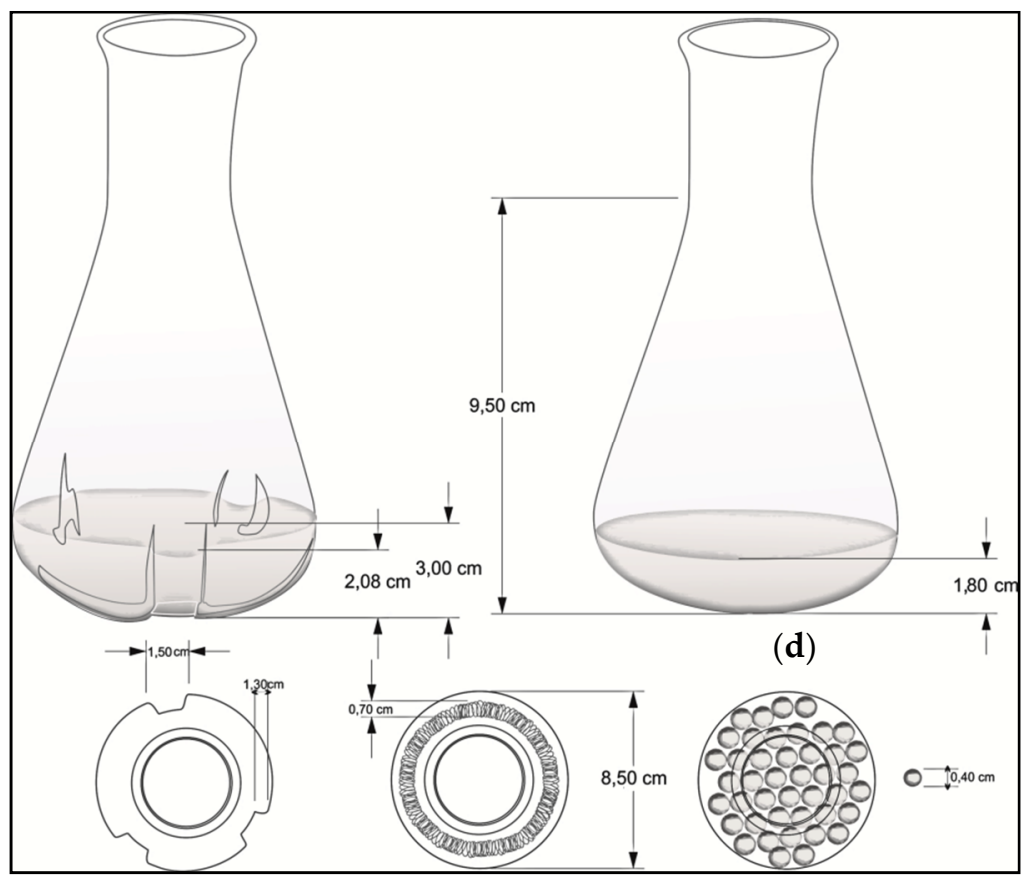

(a)

(b)

(c)

Figure 1. Flask geometries used to evaluate the mechanical stress effect on growth rate and clavulanic acid (CA) production: (a) baffled Erlenmeyer; (b) helical spring; (c) glass beads; and (d) smooth Erlenmeyer (control).

\subsection{Analytical Techniques}

Culture samples were centrifuged at $14,000 \mathrm{rpm}$ for $10 \mathrm{~min}$ at $4{ }^{\circ} \mathrm{C}$ and filtered through a $0.22 \mu \mathrm{m}$ membrane. CA was determined by High Performance Liquid Chromatography (HPLC) Agilent 1200 (Agilent Technologies, Waldbrom, Germany) equipped with a diode array detector (Agilent Technologies, Palo Alto, CA, USA) at $312 \mathrm{~nm}$, using a reverse phase ZORBAX Eclipse XDB- $\mathrm{C}_{18}$ column $(4.6 \times 150 \mathrm{~mm}, 18 \mu \mathrm{m}$ Agilent Technologies, Palo Alto, CA, USA). The mobile phase consisted of a $\mathrm{KH}_{2} \mathrm{PO}_{4}$ buffer $(\mathrm{pH} 3.2 ; 50 \mathrm{mM}$ ) and HPLC grade methanol with a flow rate of $1 \mathrm{~mL} / \mathrm{min}$. Likewise, the volume injection was $25 \mu \mathrm{L}$, and the running time was $10 \mathrm{~min}$. Due to the fact that $\mathrm{CA}$ is poorly retained in C-18 columns, a derivative procedure described by Foulstone and Reading was followed, using imidazole at a ratio of 1:3; the reaction was kept at $30^{\circ} \mathrm{C}$ for $30 \mathrm{~min}[30,31]$. This method has been validated for linearity, LOD, and LLOQ (see Supplementary Material, Figure S1) as previously described by Anurag et al. [32].

For biomass quantification the dry cell weight method was used; $1 \mathrm{~mL}$ of cell culture was periodically taken and centrifuged at $10,000 \mathrm{rpm}$, rinsed, and later dried at $105{ }^{\circ} \mathrm{C}$ for $24 \mathrm{~h} \mathrm{[2]}$.

For biomass quantification the dry cell weight method was used; $1 \mathrm{~mL}$ of cell culture was periodically taken and centrifuged at $10,000 \mathrm{rpm}$, rinsed, and later dried at $105^{\circ} \mathrm{C}$ for $24 \mathrm{~h} \mathrm{[2]}$.

\section{Results and Discussion}

\subsection{Inoculum Studies}

Inoculum size and age have been reported as important process parameters on which a significant part of the cultivation success lies. Many authors agree that the physiological and genetic state of the filamentous bacteria influences secondary metabolite production since the phase of formation of this kind of metabolites depends on the optimal growth during previous stages $[8,10,21,22]$.

Figure 2 shows the dynamics of biomass production for all inoculum sources tested. For the case of mycelium and petri dish sources, a low reproducibility was observed; a particular case was 
the difficulty to control cell morphological state and quantity, as well as the uncertainty of having a mycelium at the onset of cell death and/or fragmentation [21]. Further, mycelium from petri dishes was grown in a GYM solid medium, which could cause an extension of lag phase, after the transfer to the TSB medium. Under these circumstances, the microorganism required extra time to adapt its metabolic machinery to take advantage of the TSB nutrients.

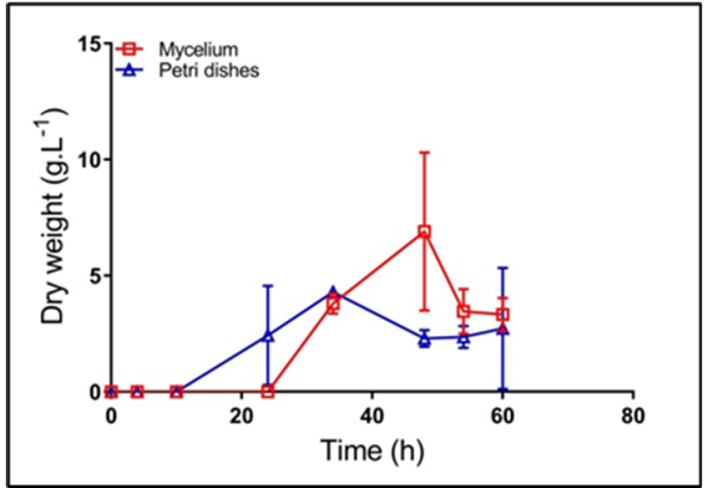

(a)

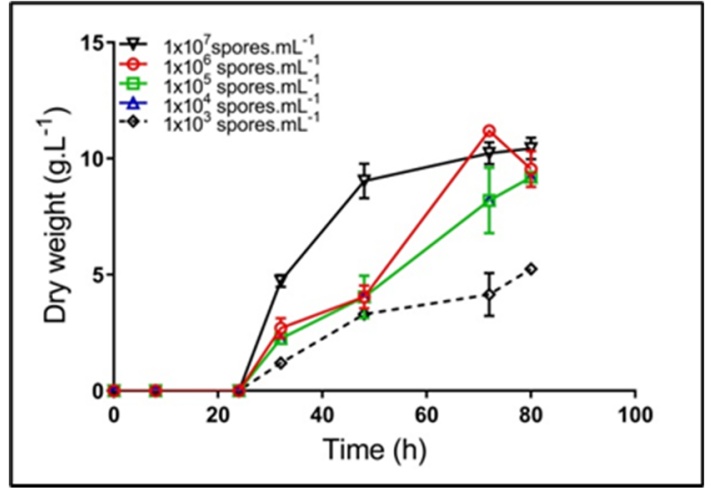

(b)

Figure 2. Kinetics of biomass synthesis of Streptomyces clavuligerus grown in a Trypticase soy broth (TSB) medium, using different inoculum sources: (a) mycelium (square) and petri dishes (triangle); (b) spore suspensions at concentrations between $1 \times 10^{3}$ and $1 \times 10^{7}$ spores $/ \mathrm{mL}$.

The highest concentration of spore suspension shows high reproducibility for the different assays (std. dev. 0.1) (Figure 2), the largest formation rate, and the greatest biomass concentration (Table 2). Based on the ANOVA results (data not shown), the inoculum source has a significant effect on $\mu$ and $t_{\mathrm{d}}$; the lower spore dilution showed the higher specific growth rate. Therefore, the spore suspension $10^{7}$ spores/mL became the best alternative for starting cultures, which is in accordance with the results of Ghojavand et al., in S. erythraea [8].

Table 2. Kinetic parameters for Streptomyces clavuligerus cultivation according to different inoculum sources.

\begin{tabular}{ccc}
\hline Inoculum Source & $\mu \mathbf{( 1 / h )}$ & $\boldsymbol{t}_{\mathbf{d}} \mathbf{( h )}$ \\
\hline Petri dishes & $0.038^{\mathrm{ab}}$ & $19.17^{\mathrm{cd}}$ \\
Mycelium & $0.032^{\mathrm{abc}}$ & $23.12^{\mathrm{bcd}}$ \\
$1 \times 10^{7}$ spores $/ \mathrm{mL}$ & $0.041^{\mathrm{a}}$ & $16.86^{\mathrm{d}}$ \\
$1 \times 10^{6}$ spores $/ \mathrm{mL}$ & $0.030^{\mathrm{bcd}}$ & $23.18^{\mathrm{bcd}}$ \\
$1 \times 10^{5}$ spores $/ \mathrm{mL}$ & $0.029^{\mathrm{bcd}}$ & $23.64^{\mathrm{bc}}$ \\
$1 \times 10^{4}$ spores $/ \mathrm{mL}$ & $0.026^{\mathrm{cd}}$ & $27.02^{\mathrm{b}}$ \\
$1 \times 10^{3}$ spores $/ \mathrm{mL}$ & $0.020^{\mathrm{d}}$ & $33.89^{\mathrm{a}}$ \\
\hline
\end{tabular}

Note: Superscripts a, b, c, and d indicate the groups generated through the least significant difference test (LSD). The same letter on different inoculum source means no significant differences among them, either for $\mu$ (specific growth rate) or $t_{\mathrm{d}}$ (doubling time).

Results from this work contrast those in which inoculum generation is carried out from stored mycelium under frozen conditions [10,21]. Apparently, the reactivated mycelium for starting fermentations, used by Neves et al. and Pinto et al., promotes the formation of secondary metabolites due to its high activity, despite its large variability (during the maximum CA production stages, the variability reached values close to $20 \%$, at reactor scale $[10,21])$. For further cultivations, the spore suspension $1 \times 10^{7}$ spores $/ \mathrm{mL}$ was used as the most favorable inoculum source; our results offered further support for the hypothesis that this condition provided uniform biomass generation. 


\subsection{Effect of Inoculum Age and Concentration on Cell Growth and CA Production}

To establish the interactions between inoculum size and age on CA production, a factorial experimental design $3^{2}$ was proposed (variables: size $(v / v)$ and age of inoculums (h); response variable: CA concentration). Results allowed for fitting a second order model, wherein the factor accounting for the interaction between variables was not significant. In contrast, the quadratic factors did show significance on CA biosynthesis ( $p$-value < 0.05) (see Supplementary Material, Table S1). Consequently, optimal values for larger CA production were estimated as $5.32 \%(v / v)$ for the inoculum size and $56.32 \mathrm{~h}$ for age, thus rendering about $29.73 \pm 4.44 \mathrm{mg} / \mathrm{L}$ of CA. Further, both the coefficient of determination $\left(r^{2}\right)$ and the adjusted-by-degree-of-freedom coefficient of determination $\left(r_{\mathrm{a}}{ }^{2}\right)$ rendered evident the low predictability of the estimated model, which agrees with the variability of the maximum CA production during cultivations (central points for the experimental design) (see Supplementary Material, Table S1 and Figure S2). The large variability of the maximum CA titers agrees with the work of Neves et al., who observed a $20 \%$ variability $(80-100 \mathrm{mg} / \mathrm{L})$ [21]. Reducing such variation requires control and monitoring of cultivation variables, such as dissolved oxygen and $\mathrm{CO}_{2}$ levels, inoculum and/or substrate concentration. Sánchez and Braña pointed out that the rapid activation of the CA biosynthetic pathway was favored by high inoculum cell density, in experiments using active spores [22]. In contrast, in this study, it was observed that increments in inoculum concentrations, above $5 \%(v / v)$, did not favor CA biosynthesis, which is consistent with other reports [1,22,33]. Accordingly, there must exist a regulatory mechanism that triggers biosynthetic pathways as a function of cell density. Thus, antibiotic production represents a response of bacteria population as a whole, and not a single property of each cell, which coincides with the nonessential nature of secondary metabolites, such as CA [22].

During inoculum preparation, cell density and age may also contribute to the premature onset of nutritional stress once the stationary phase is reached. Carbon, nitrogen, and/or phosphate deprivation renders a starving condition for the cell that may trigger the expression of genes related with programmed cell death, thus making it difficult to generate new cell material prior to cultivation using the production medium [34].

Neves et al. and Pinto et al. observed a 10\% increment in CA production using stirred tank reactors, inoculated with cells at a late exponential phase $(24 \mathrm{~h})[10,21]$. These authors used mycelium having a complete active enzymatic/metabolic machinery. In contrast, in this study, the need for obtaining larger preculture longevity was related with inoculum generation from nonactive $S$. clavuligerus spores. The lag/adaptation phase for spore growth increases prior to carbon, nitrogen, and/or phosphate catabolic activities for energy generation and cell constituents' formation. Nevertheless, from the experimental design, it was observed that the best conditions for inoculum formation were stablished at $54 \mathrm{~h}$ and $5 \%(v / v)$, starting from a spore suspension of $1 \times 10^{7}$ spores $/ \mathrm{mL}$.

\subsection{Cell Cycle and Morphology Changes in Streptomyces Clavuligerus Cell Culture}

In liquid medium, S. clavuligerus life cycle reaches an observable differentiation between primary and secondary mycelium, though without accomplishing complete sporulation (Figure 3) [4]. 


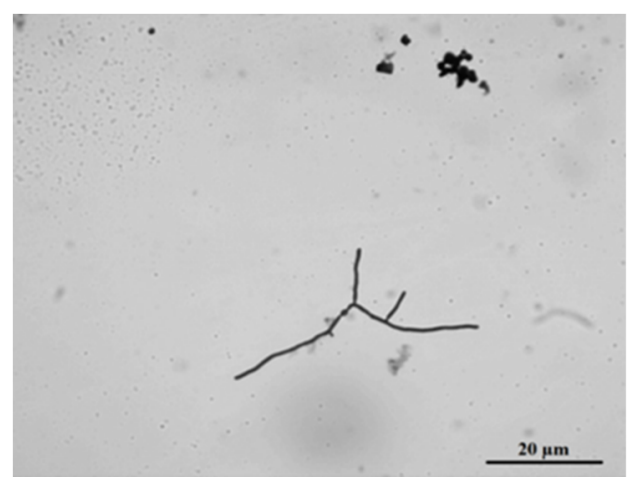

(a)

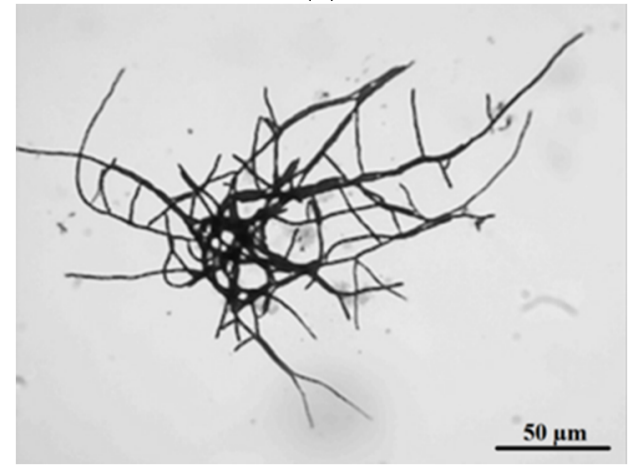

(c)

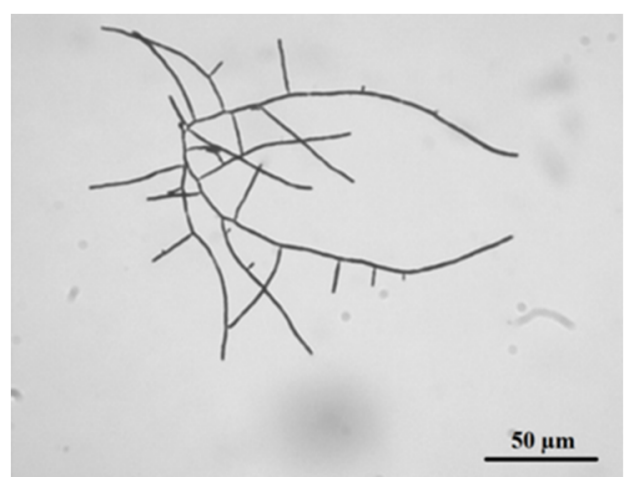

(b)

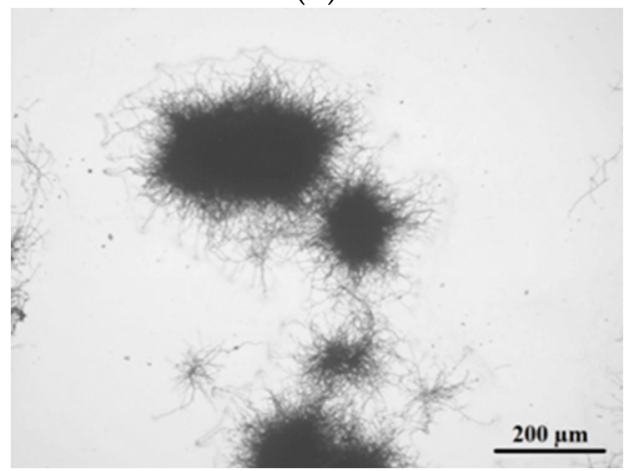

(d)

Figure 3. The life cycle of Streptomyces clavuligerus ATCC 27064 grown in TSB medium: (a) spore germination at $24 \mathrm{~h}$; (b) branched hyphae at $28 \mathrm{~h}$; (c) clump formation at $36 \mathrm{~h}$; (d) pellet establishment at $45 \mathrm{~h}$.

In TSB medium, at $24 \mathrm{~h}$, the cell cycle started with spore germination followed by hyphae growing in apical and ramified forms (Figure 3a). These results match those observed in earlier studies where, prior to germination, three different stages were described using phase-contrast microscopy: First, darkening involved changes from bright to dark phase, followed by swelling, where spore diameter doubles its size, and changes in cell wall thickness were noticed, finally ending with the emergence of germ tubes [35].

Moreover, abundant hyphae ramification and apical growth were observed at $28 \mathrm{~h}$ of culture. According to Rioseras et al., these hyphae correspond to primary mycelium (MI), which exhibited compartments formed by single nucleus hyphae and divided by internal septa, and formed a right angle with the hyphae wall [7]. The observed MI thickness in S. clavuligerus was $2 \pm 0.1 \mu \mathrm{m}$, comparable with those values reported for S. coelicolor [7].

At $36 \mathrm{~h}$ culture, MI clumps of about $600 \mu \mathrm{m}$ diameter were observed (Figure 3c); this is an intermediate state prior to pellet formation [6]. After $45 \mathrm{~h}$ of culture, pellet formation occurs, reaching $700 \mu \mathrm{m}$ of diameter (Figure 3d). Pellets are formed by two mycelium types: MI, which grows towards the pellet internal side since it was firstly developed, and secondary mycelium MII, localized towards the external part of the pellet. MII is apparently formed in a process similar to eukaryotic apoptosis where, under stress conditions, MI is dismantled and its components are reused for MII formation [4]. MII is a multinuclear mycelium; it does not possess compartments, and hyphae are composed of large multinuclear cells. MII thickness was about $0.6 \pm 0.1 \mu \mathrm{m}$. Formerly, MII was known as vegetative mycelium in solid medium; it is a precursor of spore formation since it is further coated with a hydrophobic layer, thus rendering the aerial mycelium [7]. Species such as S. venezuelae, S. griseus, S. antibioticus, S. chrysomallus, S. albidoflavus, S. brasiliensis, S. acrimycini, and S. albus, have the capacity of forming the hydrophobic layer even in submerged fermentations. Nonetheless, there are no related reports for S. clavuligerus [1,33]. 
The confocal microscopy analysis of pellets allowed for identifying a structure within which the mycelium, in its most internal part, shows a compromised membrane. The PI probe (red) penetrates cells with altered cellular permeability (Figure 4a). In contrast, cells found in the pellet peripheral side show presence of the FDA probe (green), where only viable cells with intact membrane are able to metabolize the probe employing their enzymatic machinery [36]. Yagüe et al. studied this cellular conformation using the PI and SYTO9 probes [37]. The authors demonstrated the presence of two types of mycelium in the pellet structure. The cells at the pellet interior belong to primary mycelium, formed after spore germination, and are the nutrient source for secondary mycelium, which is observed in the pellet most external area $[4,7,37]$. This structure limits the nutrient transport towards MI, e.g., oxygen causing death and favoring MII formation, which is related to antibiotic production [6]. Pellet morphology is considered not appropriate for CA production in submerged cultures, since a larger proportion of MI is present [4,38]. The transition between MI and MII is characterized by a high genomic material degradation; although currently there is not known mechanisms involved in the regulation of apoptosis, the gene ftsZ (a gen required for cell division and establishment of MI) might participate in this transition, as it was reported in S. coelicolor [39].

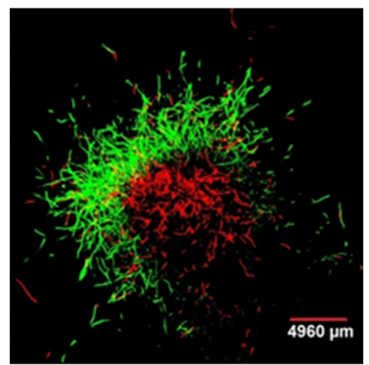

(a)

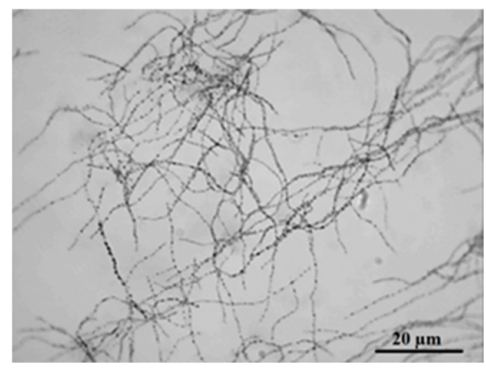

(b)

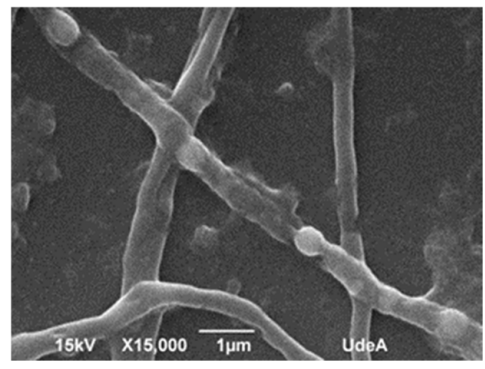

(c)

Figure 4. Observations of Streptomyces clavuligerus morphology: (a) Fluorescent staining of mycelia in TSB medium after $48 \mathrm{~h}$ of cultivation with FDA (green) and propidium iodide (red); (b) optical micrograph of mycelia at $120 \mathrm{~h}$ of culture in isolated soy protein based medium; (c) scanning electron microscopy of hyphae having separated compartments after $120 \mathrm{~h}$ of culture in isolated soy protein based medium.

Lastly, at $72 \mathrm{~h}$ culture, pellet disintegration was observed (see Supplementary Material, Figure S3) thus giving rise to disperse hyphae with no ramifications. Hyphae without branches showed septa that might suggest stages of programmed cell death. After $120 \mathrm{~h}$ cultivation, there was a biomass reduction, and the culture medium seemed more viscous. According to Kim and Kim, a layer of sticky extracellular polymers and insoluble substrates appears after pellet development, increasing medium viscosity, which is an indicator of appearance of the death phase [40].

Once pellets were transferred from TSB media, disperse nonramified MII hyphae were observed in GSPA and isolated soy protein media $(120 \mathrm{~h})$. Hyphae did show separated compartments because of subcompartmentalized sporulation guided by events of programmed cell dead; this pattern has been previously reported in S. clavuligerus by Pinilla et al. (Figure 4b) [41]. Further, membrane and cell wall residues, limiting hyphae (MII) formation, were evident (Figure 4c). This condition can be observed in Streptomyces, under starving conditions for which no sporulation in liquid media is present [14,42-46].

Morphological conditions at maximum CA production were analyzed for selected experiments. From this, Figure $4 \mathrm{~b}, \mathrm{c}$ display dispersed hyphae and subcompartmentalized sporulation (pseudo sporulation), which were continuously observed [39]. As a consequence, a relationship between the presence of disperse hyphae (MII) during pseudo sporulation and the cultivation time for the maximum CA production was established; under this condition, cells were exposed to a substrate deprivation condition for which genes involved in programmed cell death might be activated [7]. Some authors have found essential for antibiotic biosynthesis the presence of MII and the active expression of regulatory genes, e.g., $a d p A$, and the genes related to amino acid and lipid metabolism $[47,48]$. In this 
work, we did not analyze the expression of regulatory genes; however, the increase in the viscosity of the culture media due to protein (amino acids) catabolism, the emergence of intracellular compartments (programmed cell death), and the biosynthesis of CA (secondary metabolite) might indicate that genes such as $b l d G, b l d A$, and some Sigma factors were expressed, as suggested by Ferguson et al. [15]. Nevertheless, the pseudosporulation has not been correlated with secondary metabolite production as for CA.

It has been suggested there is no direct relationships between cell morphology and CA production in S. clavuligerus $[10,49,50]$. Notwithstanding, regulatory genes involved in morphological differentiation are also important for CA biosynthesis, e.g., relA, adpA, bldA, and some sigma factors [15,17,51]. Specifically, for the case of $a d p A$, a gene related to regulation of sporulation and morphogenesis, López-García et al. demonstrated that the adpA-deleted mutant of $S$. clavuligerus decreased a $10 \%$ its CA accumulation, compared to the wild type [17]. These observations underpin those of Pinilla et al., who found that the gene $a d p A$ was highly expressed when $S$. clavuligerus was grown in a culture medium that favored CA production; late genes associated to CA biosynthesis, such as ccaR and claR, were also overexpressed [41]. The former scenario might indicate a connection between morphological differentiation and CA biosynthesis, suggesting a high protease activity, reported during programmed cell death $[39,41]$. Furthermore, the use of image analysis, assisted with fluorescent probes, has not been sufficient for identifying a potential relationship between morphology and CA production $[10,52,53]$. Interestingly, results from this work show that between 96-120 h of cultivation, pseudosporulation was present because of nutritional stress, which coincided with the time for maximum CA production. Conversely, Gómez-Ríos et al. pointed out that the prevalent form of mycelia during CA maximum productivity corresponds to a thinner and dispersed mycelium, which is favored by the continuous fragmentation and high shear forces presented in a stirred tank reactor [54]. Gómez-Ríos et al. ran their experiments in fed-batch cultivations using a chemically defined medium [54]. This kind of system completely changes the CA-production dynamics, shear stress, and nutrients transport, i.e., the peak for larger CA production, which was founded by Gómez-Ríos et al., was after $130 \mathrm{~h}$ of cultivation, while results from this work show that CA biosynthesis reached its maximum peak at $120 \mathrm{~h}$ of cultivation [54]. Therefore, further studies that involve gene expression analysis and morphology might be useful for deciphering the interaction between global and/or pathway regulatory genes and secondary metabolites biosynthesis.

\subsection{The Effect of Mechanical Stress on Cell Growth and Product Biosynthesis}

The effect of shear stress on cell growth, morphology, and secondary metabolism in the Streptomyces genus has been widely studied $[1,55,56]$. Authors have observed that the scale, culture medium composition, flask and/or reactor geometry, among others, are conditioning factors that somehow modulate the shear stress influence on CA accumulation [10,23,54,57].

The effect of mechanical stress on cell growth was studied using three geometries: baffled Erlenmeyer, Erlenmeyer with a helical spring on the bottom, Erlenmeyer with spherical beads; a smooth Erlenmeyer was used as a negative control. Figure 5 shows the maximum levels of CA and biomass concentration obtained from cultures using different geometries. As observed, geometries that, by some means, provide strong mechanical stress did favor CA biosynthesis, i.e., baffled geometries, spherical beads, and the use of a helical string. The presence of baffles provides the most favorable conditions for product biosynthesis. No difference in CA production was observed when Erlenmeyer with spherical beads and helical springs were used. 


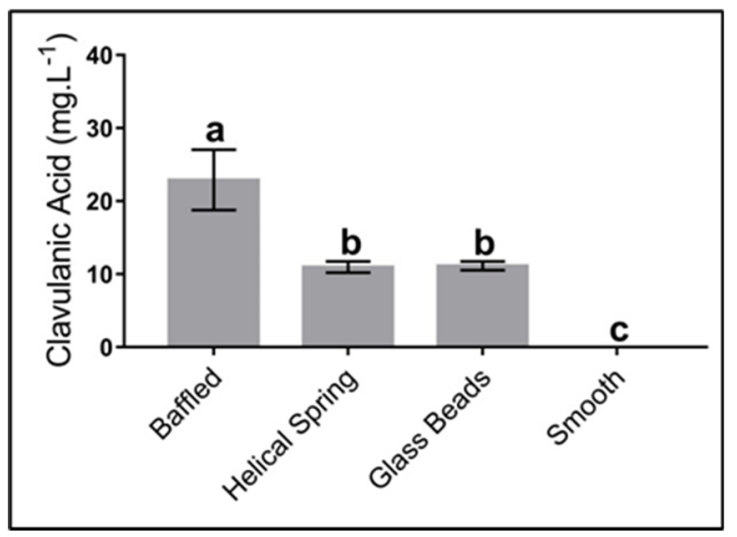

(a)

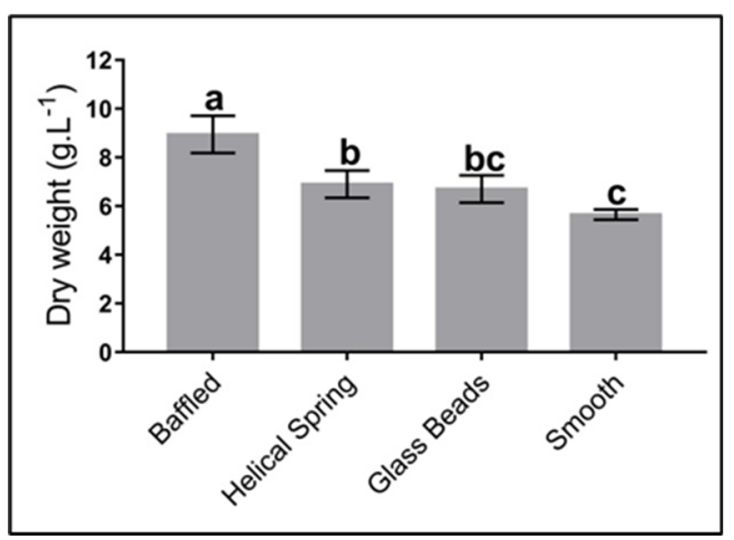

(b)

Figure 5. Effect of different flask geometries on the maximum clavulanic acid (CA) and biomass concentration in Streptomyces clavuligerus cultivations, using the complex culture medium: (a) CA; (b) biomass. All experiments were carried out under similar conditions. Letters a, b, and c indicate the groups generated through the least significant difference test (LSD). The same letter above bars means no significant differences among sources of mechanical stress.

The absence of any form of mechanical stress significantly contributes to the loss of productivity. In the presence of baffles the liquid medium spreads all over the baffle surface, thus enhancing local velocity and energy dissipation and contributing with a better mixing and larger mass transfer $[16,24,58]$. The present study did consider neither monitoring nor control of dissolved oxygen in the culture medium; however, Li et al. showed that the presence of baffles in flasks rendered volumetric mass transfer coefficient $\left(k_{\mathrm{La}}\right)$ values as large as twice the value without baffles, no matter what the filling volume for the Erlenmeyer was [58]. In contrast, geometries that included the submerged helical spring or the spherical glass beads did not provide a beneficial environment for mass transfer, perhaps due to the lack of an appropriate mixing environment and low turbulence; for a defined agitation condition, both the spring and the beads follow the direction of the fluid and have the same velocity. Consequently, $k_{\mathrm{La}}$ values for flasks containing these geometries are lower than those for the baffled Erlenmeyer.

Our findings indicate that in smooth flasks no production of clavulanic acid was reached, while the concentration of this metabolite increased up to $20 \mathrm{mg} / \mathrm{L}$ when baffled flasks were used. These results are similar to those of Pinilla et al., who obtained $24 \mathrm{mg} / \mathrm{L}$ of CA using similar culture conditions [41]. Other authors have reached a production of CA up to $100 \mathrm{mg} / \mathrm{L}$ using either baffled Erlenmeyers or stirred tanks $[20,55]$. The low CA titers obtained in this work are associated with the different cultures media we used. Although these titters are moderate, they were high enough to be correlated (or not) to different shear stress sources and the associated diverse morphological responses.

Although we carried out all our experiments in Erlenmeyer flasks, we propose an extension of the present study to a laboratory bioreactor scale where culture conditions can be controlled. The presence of multiple devices and sensors allows for a faster shift of environmental conditions and, with them, the potential morphological changes that might exist during the S. clavuligerus life cycle. These changes would eventually be associated with shear stress and/or oxygen supply.

At the morphological level, the biosynthesis of metabolites, nonassociated to energy production in filamentous microorganisms, is greater with dispersed hyphae or smaller mycelia, when compared to pellet structure; this is caused by the mass transfer limitations inside the pellet [8,59]. For the case of baffled flasks, shear stress is considerably higher in contrast to smooth flasks $[24,58]$. There are differences between flow patterns and velocity fields; this causes a greater heterogeneity in turbulence intensity. Consequently, pellets in baffled flasks have a smaller diameter and show a faster disintegration and further formation at a higher proportion of dispersed secondary mycelia, which finally will favor the production of secondary metabolites, i.e., CA [16]. 
For the case of filamentous microorganisms, e.g., S. lividans and S. clavuligerus, oxygen is highly demanded for metabolite biosynthesis, not related with energy production [60,61]. During trophophase, cells proliferate at their maximum rate, giving rise to pellets as the predominant morphology; accordingly, diffusion of oxygen to the center of this morphology becomes limiting for secondary metabolite biosynthesis, e.g., CA $[16,23,62]$. Therefore, oxygen may become the substrate that limits production since some steps of the biosynthetic pathway of CA require oxygen, e.g., the reactions involving the clavaminate synthase enzyme [63]. Nevertheless, according to Gómez-Ríos et al., under conditions of high oxygen transfer $\left(k_{L} a\right.$ values above $\left.43 \mathrm{~h}^{-1}\right)$ in rocking-motion single-use bioreactors, CA biosynthesis may not be favored; in contrast, despite the damage caused on the mycelium by high values of shear stress $\left(\tau_{\max }\right.$ values above $\left.1.4 \mathrm{~Pa}\right)$ when $S$. clavuligerus is cultivated in stirred tanks, shear stress seems to be necessary for triggering metabolic responses related with antibiotic production [54].

Commonly, promoting oxygen transfer through pellet morphology requires increasing the agitation rate and consequently increasing shear stress. Such a mechanical perturbation might induce a physiological response that ends up in cell wall and membrane disintegration, thereby triggering programmed cell death $[50,64]$. However, fragmentation caused by shear stress may lead to the formation of short hyphae capable of growing and reproducing, and thus producing antibiotics as long as some conditions are given in the stirred culture system; among others, a tip speed below $800 \mathrm{rpm}$, a carbon, phosphorus, and nitrogen availability, and a threshold value of dissolved oxygen between 20 and $80 \%$ during cultivation must be secured; the former condition is sufficiently provided by the baffled or even helical spring flasks used in this work [23,54,57].

Figure 6 shows the mycelium morphology as a response to the mechanical stress caused by different geometries; samples were taken after $72 \mathrm{~h}$ of cultivation for analysis under scanning electron microscopy. Micrographs show a strong affectation on the mycelial cell wall in experiments wherein baffled Erlenmeyer were used (Figure 6a), represented by a nonregular surface and lack of continuity of the filament which might indicate cell break. In contrast, in smooth Erlenmeyer (Figure 6d), mycelium appears continuous in its cell wall (nonbroken), which denotes cell integrity and viability. In the case of helical spring or glass beads (Figure $6 \mathrm{~b}, \mathrm{c}$ ), cell damage does not seem evident, compared to smooth flasks, although it is possible to identify some slight discontinuity zones on the filament. Pinto et al., Roubos et al., and Belmar-Beiny and Thomas showed the high sensitivity of S. clavuligerus mycelium to different sources of mechanical stress, including agitation $[10,49,50]$. For S. erythraea, it has been shown that the predominance of the loosely grouping mycelium without specific shape-a clump structure-contributes to erythromycin biosynthesis, because of the favorable conditions for nutrients transport through filaments, as well as nystatin production (antifungal antibiotic). Jonsbu et al. reported that the increasing of pellet size over a critical value (not determined) discourages nystatin accumulation and cell growth, given the difficulty for metabolic activities at the center of the pellet [65].

The presence of secondary mycelium is indispensable for antibiotic production, when utilizing the Streptomyces species [5-7]. However, there is no consensus about a morphological nature that determines secondary metabolites accumulation. Such is the case of rapamycin (antibiotic) and avermectin (insecticide and pesticide) biosynthesis using S. hygroscopicus and S. avermitilis, respectively. Unlike this work, the authors found that pellet morphology promotes secondary metabolites excretion. In S. hygroscopicus and S. avermitilis, the growth of longer filaments and a high frequency of mycelia branching at the pellet periphery were present $[66,67]$. 


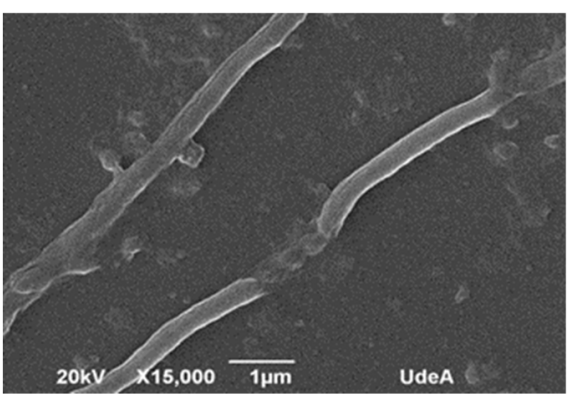

(a)

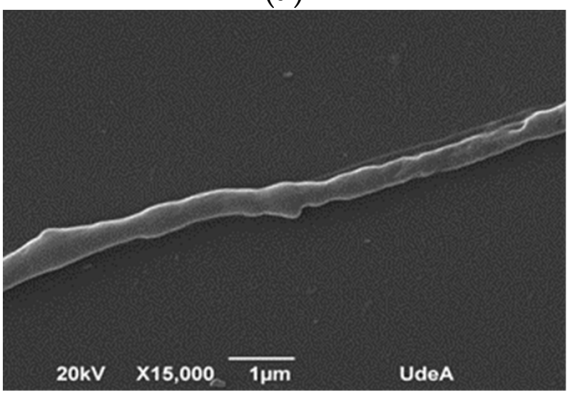

(c)

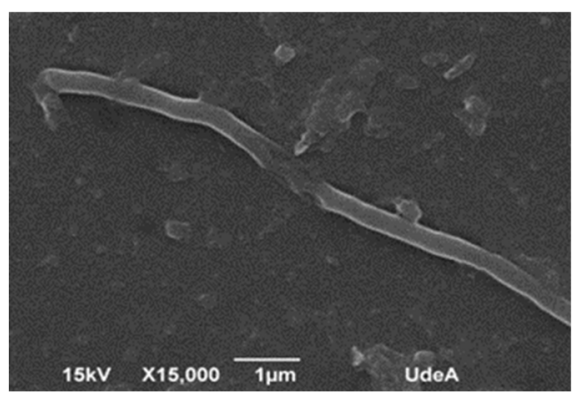

(b)

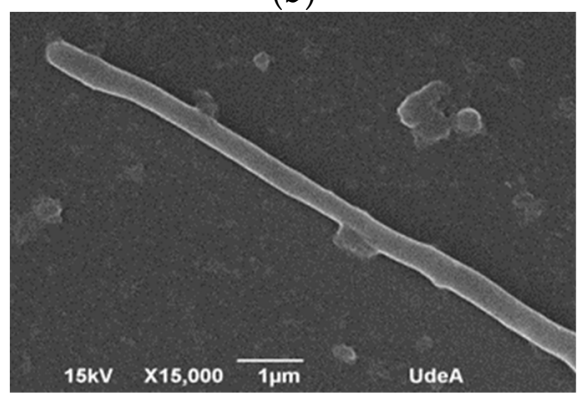

(d)

Figure 6. Scanning electron microscopy of Streptomyces clavuligerus at $72 \mathrm{~h}$ culture in: (a) baffled flask, (b) flask with helical spring on the bottom, (c) flasks with submerged glass beads, and (d) smooth flask.

\section{Conclusions}

This work aimed at identifying a potential relationship that might exist between $S$. clavuligerus ATCC 27064 morphology and CA biosynthesis. For this, modified culture conditions such as size and age of inoculum, and geometry of the fermentation flasks, were tested.

Primarily, the results provide clear evidence that high density spore suspensions $\left(1 \times 10^{7}\right.$ spores $\left./ \mathrm{mL}\right)$ represent the best inoculum source for S. clavuligerus cell suspension culture. Under this condition, the highest specific growth rate and high reproducibility were attained, which is consistent with reports from other filamentous microorganisms, e.g., S. erythraea [8]. Inoculum concentration and age play an important role in CA biosynthesis. An inoculum equivalent to $5 \%$ as well as a $54 \mathrm{~h}$ incubation is recommended from the present research; in addition, this investigation suggests that $120 \mathrm{~h}$ of cultivation and a culture medium based on isolated soy protein are appropriate settings for CA biosynthesis.

Further, S. clavuligerus follows a cell cycle comparable to other Streptomyces species, such as S. coelicolor and S. hygroscopicus $[13,66]$. S. clavuligerus can reach the pellet conditions after going through the clump morphology. During its cell cycle, the cells form two mycelial types that differ in the order of synthesis, thickness, and relationship with CA biosynthesis. The pellet morphology presents a primary mycelium formation within the pellet and secondary mycelium in the periphery, similarly to S. coelicolor [7].

The study shows that as long as dispersed secondary mycelium of $S$. clavuligerus is in a pseudosporulation stage (hyphae with separated compartments), which is reached by programmed cell death and nutrient starvation [34,38,59], higher titers of CA are achieved; this phenomenon was observed in all experiments and was independent of flask geometry.

Although it is documented that $S$. clavuligerus is susceptible to shear stress generated by agitation and aeration $[10,24,54,57]$, its response to different flask geometries, which characterizes the mechanical stress, has not been studied. In this work, differences regarding bacterial morphology and CA production were evident while using different mechanical stress sources. Baffled Erlenmeyer, helical springs, and circular glass beads did provide diverse mechanical stress conditions and favorable environmental conditions necessary for CA biosynthesis. The most suitable condition was the baffled 
Erlenmeyer since it allows for better mixing conditions and an improved capacity for mass transfer; the above stems from S. clavuligerus having the ability to generate pellets, where diffusion of nutrients, e.g., oxygen, towards their core is critical for CA biosynthesis. Consequently, geometries that increase shear stress, e.g., baffled or coiled flasks, promote smaller pellets and a quick disintegration of these in dispersed secondary mycelia, which begins the pseudosporulation process, easing CA accumulation, as documented in the present work. These outcomes greatly contribute to improving the understanding of antibiotic biosynthesis in the Streptomyces species.

Supplementary Materials: The following are available online at http://www.mdpi.com/2227-9717/8/9/1038/s1, Figure S1: Calibration curve for quantification of clavulanic acid, Figure S2: Three-dimensional response surface plot showing the simultaneous effects of inoculum and size on CA concentration, Figure S3: Pellet disintegration of Streptomyces clavuligerus ATCC 27064 grown in TSB medium after $72 \mathrm{~h}$ of culture, Table S1. Analysis of variance applied to the regression model used for the clavulanic acid concentration.

Author Contributions: J.Y.-G.: conceived the study, designed, and performed all the experiments, and drafted the manuscript. C.C.-M., L.P. and L.F.T.: developed and executed statistical tests, and carried out image analysis for all the microscopies. R.R.-E.: supervised the research work, interpreted the results, corrected and wrote the manuscript, and serve as corresponding author. All authors have read and approved the final manuscript.

Funding: This work was supported by Departamento Administrativo de Ciencia, Tecnología $e$ Innovación-COLCIENCIAS-Colombia (Grant Number 111566945929).

Acknowledgments: L.F.T and L.P. thank COLCIENCIAS-Colombia for scholarships.

Conflicts of Interest: The authors declare no conflict of interest regarding the publication of this paper.

\section{References}

1. Saudagar, P.S.; Survase, S.A.; Singhal, R.S. Clavulanic acid: A review. Biotechnol. Adv. 2008, 26, 335-351. [CrossRef] [PubMed]

2. Gouveia, E.R.; Baptista-Neto, A.; Azevedo, A.G.; Badino-jr, A.C.; Hokka, C.O. Improvement of clavulanic acid production by Streptomyces clavuligerus in medium containing soybean derivatives. Microbiol. Biotechnol. 1999, 15, 623-627. [CrossRef]

3. Higgens, C.E.; Kastner, R.E. Streptomyces clavuligerus sp. nov., a $\beta$-lactam antibiotic producer. Syst. Bacteriol. 1971, 21, 326-331. [CrossRef]

4. Manteca, A.; Sanchez, J. Streptomyces developmental cycle and secondary metabolite production. In Current Research, Technology and Education Topics in Applied Microbiology and Microbial Biotechnology, 1st ed.; Méndez-Vilas, A., Ed.; FORMATEX: Bajadoz, Spain, 2010; Volume 2, pp. 560-566, ISBN 978-84-614-6195-0.

5. Yagüe, P.; Rodríguez-García, A.; López-García, M.T.; Martín, J.F.; Rioseras, B.; Sánchez, J.; Manteca, Á. Transcriptomic analysis of Streptomyces coelicolor differentiation in solid sporulating cultures: First compartmentalized and second multinucleated mycelia have different and distinctive transcriptomes. PLoS ONE 2013, 8, 1-14. [CrossRef] [PubMed]

6. Manteca, A.; Sánchez, J.; Jung, H.R.; Schwämmle, V.; Jensen, O.N. Quantitative proteomics analysis of Streptomyces coelicolor development demonstrates that onset of secondary metabolism coincides with hypha differentiation. Mol. Cell. Proteom. 2010, 9, 1423-1436. [CrossRef] [PubMed]

7. Rioseras, B.; López-García, M.T.; Yagüe, P.; Sánchez, J.; Manteca, Á. Mycelium differentiation and development of Streptomyces coelicolor in lab-scale bioreactors: Programmed cell death, differentiation, and lysis are closely linked to undecylprodigiosin and actinorhodin production. Bioresour. Technol. 2014, 151, 191-198. [CrossRef]

8. Ghojavand, H.; Bonakdarpour, B.; Heydarian, S.M.; Hamedi, J. The inter-relationship between inoculum concentration, morphology, rheology and erythromycin productivity in submerged cultivation of Saccharopolyspora erythraea. Braz. J. Chem. Eng. 2011, 28, 564-574. [CrossRef]

9. Yang, Y.K.; Morikawa, M.; Shimizu, H.; Shioya, S.; Suga, K.I.; Nihira, T.; Yamada, Y. Image analysis of mycelial morphology in virginiamycin production by batch culture of Streptomyces virginiae. J. Ferment. Bioeng. 1996, 81, 7-12. [CrossRef]

10. Pinto, L.S.; Vieira, L.M.; Pons, M.N.; Fonseca, M.M.R.; Menezes, J.C. Morphology and viability analysis of Streptomyces clavuligerus in industrial cultivation systems. Bioprocess Biosyst. Eng. 2004, 26, 177-184. [CrossRef] 
11. Stocks, S.M.; Thomas, C.R. Viability, strength, and fragmentation of Saccharopolyspora erythraea in submerged fermentation. Biotechnol. Bioeng. 2001, 75, 702-709. [CrossRef]

12. Manteca, Á.; Fernandez, M.; Sanchez, J. Mycelium development in Streptomyces antibioticus ATCC 11891 occurs in an orderly pattern which determines multiphase growth curves. BMC Microbiol. 2005, 5, 1-11. [CrossRef] [PubMed]

13. Manteca, A.; Alvarez, R.; Salazar, N.; Yagüe, P.; Sanchez, J. Mycelium differentiation and antibiotic production in submerged cultures of Streptomyces coelicolor. Appl. Environ. Microbiol. 2008, 74, 3877-3886. [CrossRef] [PubMed]

14. Kim, J.; Hancock, I.C. Pellet forming and fragmentation in liquid culture of Streptomyces griseus. Biotechnol. Lett. 2000, 22, 189-192. [CrossRef]

15. Ferguson, N.L.; Peña-Castillo, L.; Moore, M.A.; Bignell, D.R.D.; Tahlan, K. Proteomics analysis of global regulatory cascades involved in clavulanic acid production and morphological development in Streptomyces clavuligerus. J. Ind. Microbiol. Biotechnol. 2016, 43, 537-555. [CrossRef] [PubMed]

16. Marín-Palacio, L.D.; Gamboa-Suasnavart, R.A.; Valdez-Cruz, N.A.; Servín-González, L.; Córdova-Aguilar, M.S.; Soto, E.; Klöckner, W.; Büchs, J.; Trujillo-Roldán, M.A. The role of volumetric power input in the growth, morphology, and production of a recombinant glycoprotein by Streptomyces lividans in shake flasks. Biochem. Eng. J. 2014, 90, 224-233. [CrossRef]

17. López-García, M.T.; Santamarta, I.; Liras, P. Morphological differentiation and clavulanic acid formation are affected in a Streptomyces clavuligerus adpA-deleted mutant. Microbiol 2010, 156, 2354-2365. [CrossRef]

18. Cho, H.S.; Jo, J.C.; Shin, C.H.; Lee, N.; Choi, J.S.; Cho, B.K.; Roe, J.H.; Kim, C.W.; Kwon, H.J.; Yoon, Y.J. Improved production of clavulanic acid by reverse engineering and overexpression of the regulatory genes in an industrial Streptomyces clavuligerus strain. J. Ind. Microbiol. Biotechnol. 2019, 46, 1205-1215. [CrossRef]

19. Salem-Bekhit, M.M.; Alanazi, F.K.; Alsarra, I.A. Improvement and enhancement of clavulanic acid production in Streptomyces clavuligerus using vegetable oils. Afr. J. Biotechnol. 2010, 9, 6806-6812.

20. Maranesi, G.L.; Baptista-Neto, A.; Hokka, C.O.; Badino, A.C. Utilization of vegetable oil in the production of clavulanic acid by Streptomyces clavuligerus ATCC 27064. World J. Microbiol. Biotechnol. 2005, 21, 509-514. [CrossRef]

21. Neves, A.A.; Vieira, L.M.; Menezes, J.C. Effects of preculture variability on clavulanic acid fermentation. Biotechnol. Bioeng. 2001, 72, 628-633. [CrossRef]

22. Sánchez, L.; Braña, A.F. Cell density influences antibiotic biosynthesis in Streptomyces clavuligerus. Microbiology 1996, 142, 1209-1220. [CrossRef] [PubMed]

23. Rosa, J.C.; Neto, A.B.; Hokka, C.O.; Badino, A.C. Influence of dissolved oxygen and shear conditions on clavulanic acid production by Streptomyces clavuligerus. Bioprocess Biosyst. Eng. 2005, 27, 99-104. [CrossRef] [PubMed]

24. Peter, C.P.; Suzuki, Y.; Rachinskiy, K.; Lotter, S.; Büchs, J. Volumetric power consumption in baffled shake flasks. Chem. Eng. Sci. 2006, 61, 3771-3779. [CrossRef]

25. Manteca, A.; Ye, J.; Sánchez, J.; Jensen, O.N. Phosphoproteome analysis of Streptomyces development reveals extensive protein phosphorylation accompanying bacterial differentiation. J. Proteome Res. 2011, 10, 5481-5492. [CrossRef]

26. Hopwood, D.A.; Bibb, M.J.; Chater, K.F.; Kieser, T.; Bruton, C.J.; Kieser, H.M.; Lydiate, D.J.; Smith, C.P.; Ward, J.M.; Schrempf, H. Genetic Manipulation of Streptomyces: A Laboratory Manual, 1st ed.; The John Innes Foundation: Norwich, UK, 1985; pp. 1-356, ISBN 0-7084-0036-0.

27. Romero, J.; Liras, P.; Martín, J.F. Utilization of ornithine and arginine as specific precursors of clavulanic acid. Appl. Environ. Biotechnol. 1986, 52, 892-897. [CrossRef]

28. Kofroňová, O.; Nguyen, L.D.; Weiser, J.; Benada, O. Streptomycetes cultured on glass beads: Sample preparation for SEM. Microsc. Res. Tech. 2002, 58, 111-113. [CrossRef]

29. Bray, D. Critical point drying of biological specimens for scanning electron microscopy. In Methods in Biotechnology: Supercritical Fluid Methods and Protocols, 1st ed.; Williams, J.R., Clifford, A.A., Eds.; Humana Press: Totowa, NJ, USA, 2000; Volume 13, pp. 235-243, ISBN 978-0-89603-571-3.

30. Foulstone, M.; Reading, C. Assay of amoxicillin and clavulanic acid, the components of augmentin, in biological fluids with high-performance liquid chromatography. Antimicrob. Agents Chemother. 1982, 22, 753-762. [CrossRef] 
31. Ramirez-Malule, H.; Junne, S.; López, C.; Zapata, J.; Sáez, A.; Neubauer, P. An improved HPLC-DAD method for clavulanic acid quantification in fermentation broths of Streptomyces clavuligerus. J. Pharm. Biomed. Anal. 2016, 120, 241-247. [CrossRef]

32. Anurag, M.; Gurumurthy, M.; Mishra, A.; Shukla, R. Development and method validation on stress degradation studies of cefpodoxime proxetil and clavulanic acid in dosage form by HPLC method. Der Pharma. Lett. 2015, 7, 81-92.

33. Ser, H.L.; Law, J.W.F.; Chaiyakunapruk, N.; Jacob, S.A.; Palanisamy, U.D.; Chan, K.G.; Goh, B.H.; Lee, L.H. Fermentation conditions that affect clavulanic acid production in Streptomyces clavuligerus: A systematic review. Front. Microbiol. 2016, 7, 522. [CrossRef]

34. Yagüe, P.; López-García, M.T.; Rioseras, B.; Sánchez, J.; Manteca, Á. Pre-sporulation stages of Streptomyces differentiation: State-of-the-art and future perspectives. FEMS Microbiol. Lett. 2013, 342, 79-88. [CrossRef] [PubMed]

35. Elliot, M.A.; Flärdh, K. Streptomycete Spores; John Wiley and Sons Ltd.: Hoboken, NJ, USA, 2012; pp. 1-9.

36. Fontvieille, D.A.; Outaguerouine, A.; Thevenot, D.R. Fluorescein diacetate hydrolysis as a measure of microbial activity in aquatic systems: Application to activated sludges. Environ. Technol. 1992, 13, 531-540. [CrossRef]

37. Yagüe, P.; Rodríguez-García, A.; López-García, M.T.; Rioseras, B.; Martín, J.F.; Sánchez, J. Transcriptomic analysis of liquid non-sporulating Streptomyces coelicolor cultures demonstrates the existence of a complex differentiation comparable to that occurring in solid sporulating cultures. PLoS ONE 2014, 9, 1-13. [CrossRef] [PubMed]

38. Yagüe, P.; Rioseras, B.; Sanchez, J.; Manteca, A. New insights on the development of Streptomyces and their relationships with secondary metabolite production. Curr. Trends Microbiol. 2012, 8, 65-73.

39. Yagüe, P.; Willemse, J.; Koning, R.I.; Rioseras, B.; López-García, M.T.; Gonzalez-Quiñonez, N.; Lopez-Iglesias, C.; Shliaha, P.V.; Rogowska-Wrzesinska, A.; Koster, A.J.; et al. Subcompartmentalization by cross-membranes during early growth of Streptomyces hyphae. Nat. Commun. 2016, 7, 1-11. [CrossRef]

40. Kim, Y.M.; Kim, J.H. Formation and dispersion of mycelial pellets of Streptomyces coelicolor A3(2). J. Microbiol. 2004, 42, 64-67.

41. Pinilla, L.; Toro, L.F.; Laing, E.; Alzate, J.F.; Ríos-Estepa, R. Comparative transcriptome analysis of Streptomyces clavuligerus in response to favorable and restrictive nutritional conditions. Antibiotics 2019, 8, 96. [CrossRef]

42. Kendrickt, K.E.; Ensign, J.C. Sporulation of Streptomyces griseus in submerged culture. J. Bacteriol. 1983, 155, 357-366. [CrossRef]

43. Glazebrook, M.A.; Doull, J.L.; Stuttard, C.; Vining, L.C. Sporulation of Streptomyces Venezuelae in submerged cultures. J. Gen. Microbiol. 1990, 136, 581-588. [CrossRef]

44. Gottlieb, D.; Legator, M. The growth and metabolic behavior of Streptomyces Venezuelae in liquid culture. Mycol. Soc. Am. 1953, 45, 507-515. [CrossRef]

45. Bradley, S.G.; Ritzi, D. Composition and ultrastructure of Streptomyces Venezuelae. J. Bacteriol. 1968, 95, 2358-2364. [CrossRef] [PubMed]

46. Hobbs, G.; Frazer, C.M.; Gardner, D.C.J.; Cullum, J.A.; Oliver, S.G. Dispersed growth of Streptomyces in liquid culture. Appl. Microbiol. Biotechnol. 1989, 31, 272-277. [CrossRef]

47. Manteca, A.; Jung, H.R.; Schwaömmle, V.; Jensen, O.N.; Sanchez, J. Quantitative proteome analysis of Streptomyces coelicolor nonsporulating liquid cultures demonstrates a complex differentiation process comparable to that occurring in sporulating solid cultures. J. Proteome Res. 2010, 9, 4801-4811. [CrossRef] [PubMed]

48. Beites, T.; Oliveira, P.; Rioseras, B.; Pires, S.D.S.; Oliveira, R.; Tamagnini, P.; Moradas-Ferreira, P.; Manteca, Á.; Mendes, M.V. Streptomyces natalensis programmed cell death and morphological differentiation are dependent on oxidative stress. Sci. Rep. 2015, 5, 1-15.

49. Belmar-Beiny, M.T.; Thomas, C.R. Morphology and clavulanic acid production of Streptomyces clavuligerus: Effect of stirrer speed in batch fermentations. Biotechnol. Bioeng. 1990, 37, 456-462. [CrossRef]

50. Roubos, J.A.; Krabben, P.; Luiten, R.G.M.; Verbruggen, H.B.; Heijnen, J.J. A quantitative approach to characterizing cell lysis caused by mechanical agitation of Streptomyces clavuligerus. Biotechnol. Prog. 2001, 17, 336-347. [CrossRef]

51. Ryu, Y.G.; Jin, W.; Kim, J.Y.; Kim, J.Y.; Lee, S.H.; Lee, K.J. Stringent factor regulates antibiotics production and morphological differentiation of Streptomyces clavuligerus. J. Microbiol. Biotechnol. 2004, 14, 1170-1175. 
52. Sebastine, I.M.; Stocks, S.M.; Cox, P.W.; Thomas, C.R. Characterisation of percentage viability of Streptomyces clavuligerus using image analysis. Biotechnol. Tech. 1999, 13, 419-423. [CrossRef]

53. Nurmohamadi, M.; Pourghassem, H. Clavulanic acid production estimation based on color and structural features of Streptomyces clavuligerus bacteria using self-organizing map and genetic algorithm. Comput. Methods Programs Biomed. 2014, 114, 337-348. [CrossRef]

54. Gómez-Ríos, D.; Junne, S.; Neubauer, P.; Ochoa, S.; Ríos-Estepa, R.; Ramírez-Malule, H. Characterization of the metabolic response of Streptomyces clavuligerus to shear stress in stirred tanks and single-use 2D rocking motion bioreactors for clavulanic acid production. Antibiotics 2019, 8, 168. [CrossRef]

55. Neto, A.B.; Hirata, D.B.; Cassiano Filho, L.C.M.; Bellão, C.; Júnior, A.C.B.; Hokka, C.O. A study on clavulanic acid production by Streptomyces clavuligerus in batch, fed-batch and continuous processes. Braz. J. Chem. Eng. 2005, 22, 557-563. [CrossRef]

56. Sánchez Pérez, J.A.; Rodríguez Porcel, E.M.; Casas López, J.L.; Fernández Sevilla, J.M.; Chisti, Y. Shear rate in stirred tank and bubble column bioreactors. Chem. Eng. J. 2006, 124, 1-5. [CrossRef]

57. Cerri, M.O.; Badino, A.C. Shear conditions in clavulanic acid production by Streptomyces clavuligerus in stirred tank and airlift bioreactors. Bioprocess Biosyst. Eng. 2012, 35, 977-984. [CrossRef]

58. Li, C.; Xia, J.Y.; Chu, J.; Wang, Y.H.; Zhuang, Y.P.; Zhang, S.L. CFD analysis of the turbulent flow in baffled shake flasks. Biochem. Eng. J. 2012, 70, 140-150. [CrossRef]

59. Gamboa-Suasnavart, R.A.; Valdez-Cruz, N.A.; Cordova-Dávalos, L.E.; Martínez-Sotelo, J.A.; Servín-González, L.; Espitia, C.; Trujillo-Roldán, M.A. The O-mannosylation and production of recombinant APA (45/47 KDa) protein from Mycobacterium tuberculosis in Streptomyces lividans is affected by culture conditions in shake flasks. Microb. Cell Fact. 2011, 10, 1-11. [CrossRef] [PubMed]

60. Zacchetti, B.; Smits, P.; Claessen, D. Dynamics of pellet fragmentation and aggregation in liquid-grown cultures of Streptomyces lividans. Front. Microbiol. 2018, 9, 1-10. [CrossRef]

61. Gamboa-Suasnavart, R.A.; Valdez-Cruz, N.A.; Gaytan-Ortega, G.; Reynoso-Cereceda, G.I.; Cabrera-Santos, D.; López-Griego, L.; Klöckner, W.; Büchs, J.; Trujillo-Roldán, M.A. The metabolic switch can be activated in a recombinant strain of Streptomyces lividans by a low oxygen transfer rate in shake flasks. Microb. Cell Fact. 2018, 17, 1-12. [CrossRef]

62. Yegneswaran, P.K.; Gray, M.R.; Thompson, B.G. Effect of dissolved oxygen control on growth and antibiotic production in Streptomyces clavuligerus fermentations. Biotechnol. Prog. 1991, 7, 246-250. [CrossRef]

63. Martínez-Burgo, Y.; Álvarez-Álvarez, R.; Rodríguez-García, A.; Liras, P. The pathway specific-regulator ClaR of Streptomyces clavuligerus has a global effect on the expression of genes for secondary metabolism and differentiation. Appl. Environ. Microbiol. 2015, 81, 6637-6648. [CrossRef]

64. Olmos, E.; Mehmood, N.; Haj Husein, L.; Goergen, J.L.; Fick, M.; Delaunay, S. Effects of bioreactor hydrodynamics on the physiology of Streptomyces. Bioprocess Biosyst. Eng. 2013, 36, 259-272. [CrossRef]

65. Jonsbu, E.; McIntyre, M.; Nielsen, J. The influence of carbon sources and morphology on nystatin production by Streptomyces noursei. J. Biotechnol. 2002, 95, 133-144. [CrossRef]

66. Qi, H.; Zhao, S.; Fu, H.; Wen, J.; Jia, X. Coupled cell morphology investigation and metabolomics analysis improves rapamycin production in Streptomyces hygroscopicus. Biochem. Eng. J. 2014, 91, 186-195. [CrossRef]

67. Yin, P.; Wang, Y.H.; Zhang, S.L.; Chu, J.; Zhuang, Y.P.; Chen, N.; Li, X.F.; Wu, Y.B. Effect of mycelial morphology on bioreactor performance and avermectin production of Streptomyces avermitilis in submerged cultivations. J. Chin. Inst. Chem. Eng. 2008, 39, 609-615. [CrossRef]

(C) 2020 by the authors. Licensee MDPI, Basel, Switzerland. This article is an open access article distributed under the terms and conditions of the Creative Commons Attribution (CC BY) license (http://creativecommons.org/licenses/by/4.0/). 